\title{
AGÊNCIAS REGULADORAS E PROTEÇÃO DO CONSUMIDOR DE SERVIÇOS DE TELECOMUNICAÇÕES
}

\author{
OTHON MORENo DE MEDEIROS Alves
}

1. Federal Communications Commission (FCC): embrião das agências de telecomunicaçōes. 2. Agência Nacional de Telecomunicaçōes (ANATEL): origem e funções genéricas. 3. ANATEL e Proteção do Consumidor. 4. A Agência e a defesa da concorrência. 5. Considerações Finais. 6. Referências Bibliográficas.

A ênfase constitucional à proteção do consumidor está dentre as mais duradouras e incisivas influências da Carta de 1988 à realidade social e à inovação jurídica. Garantida como direito fundamental (Art. $5^{\circ}$, XXXII) e princípio da ordem econômica brasileira (Art. 170, V), a defesa do consumidor tornou-se significativa missão político-administrativa de todos os entes federativos.

A década seguinte à promulgação da Constituição trouxe grandes alterações à posição do Estado brasileiro e sua participação no fornecimento de serviços públicos. A introdução de medidas legislativas reformadoras, de que são paradigmáticas as Emendas Constitucionais $n^{\circ} \mathrm{s}$. 8/1995 e 9/1995, visaram relocar a Administração Pública na estrutura econômica brasileira, de uma posição firme como fornecedora direta de serviços públicos a um novo posto como reguladora da atividade de concessionária particulares.

Instituído como agente eminentemente fiscalizador dos fornecedores de serviços públicos, o Estado assume obrigações ainda mais severas quanto à proteção do consumidor. No campo das telecomunicações e das comunicações de massa, a considerável amplitude da defesa do consumidor pode incluir desde a proteção contra tarifas abusivas até a promoção de profundos valores constitucionais como a liberdade de expressão e a defesa da privacidade, sempre sob a tutela administrativa de um mesmo órgão regulador, a Agência Nacional de Telecomunicações - ANATEL, no caso brasileiro.

A análise do poder desse órgão na proteção do consumidor requer primeiramente detalhada observação de suas origens no direito administrativo americano e seu desenvolvimento na ordem constitucional dos Estados Unidos como agente de pro- 
teção do consumidor e da concorrência. Posteriormente, deve-se examinar a própria origem da agência brasileira, seus objetivos institucionais e seus poderes efetivos na defesa do consumidor e na promoção de um mercado aberto e de livre concorrência.

\section{Federal Communications Commission (FCC): embriäo das agências de} telecomunicações

\section{A) FCC como agência reguladora}

A influência do Direito Administrativo americano na construção da Administração Pública brasileira contemporânea é inegável. Dele provêm tanto a figura das "Agências Reguladoras" quanto a unificação legal dos procedimentos administrativos (Lei 9.784/1999)'.

O conceito da Agency é, na realidade, bastante amplo no Direito Administrativo americano contemporâneo. Conforme prevê a Lei do Procedimento Administrativo (Administrative Procedure Act), o termo pode "significar qualquer autoridade do Governo dos Estados Unidos", exceto o Congresso, os Tribunais e os governos de territórios, possessões e do Distrito de Colúmbia ${ }^{2}$.

As primeiras agências federais americanas foram estabelecidas já com a primeira legislatura (1789-1790) ${ }^{3}$. No entanto, enquanto instituição do direito administrativo americano marcada simultaneamente por funções executivas e autonomia da Presidência da República, a Agency inicia-se como o estabelecimento do Instituto Smithsonian, em $1846^{4}$. Estruturado como pessoa jurídica autônoma (autárquica) fundacional, o Smithsonian foi o estopim da formação da burocracia autônoma que atua através das agências.

As circunstâncias econômicas do final do século XIX, especialmente o surgimento de grandes conglomerados econômicos, forçaram a geração de duas grandes inovações na administração federal americana. A Lei Antitruste (Sherman Antitrust Act, 1890) foi a novidade mais celebrada, mas imprimiu impacto ainda mais profundo no governo a instituição da Interstate Commerce Commission (ICC), em 1887, a primeira agência reguladora federal ${ }^{5}$ dos Estados Unidos $^{6}$, responsável inicialmente pela fiscalização e regulamentação do transporte ferroviário interestadual.

A ICC seria a primeira de uma série de agências criadas à margem dos Ministérios (Departments) e dirigidas por conselhos independentes, com poderes semilegislativos e estruturado sistema procedimental e compostos por membros sem responsabilidade direta perante o Presidente da República e com mandatos extensos e determinados.

1 Cavalcanti, 2000, p. 270.

2 Schwartz, 1988, p. 20

3 Shwartz.

4 Stilman, 1992, p. 58.

5 De fato, a primeira Regulatory Agency Federal; a própria ICC foi criada com base em modelos estaduais preexistentes.

6 Stilman, 1992, p. 62. 
A autonomia plena em relação à Presidência, em aparente contrariedade com as prerrogativas constitucionais do chefe do Poder Executivo, somente seria fixado pela Suprema Corte em 1935, na decisão do caso Humphrey's Executor v. United States. Esta decisão invalidou a demissão ad nutum de um conselheiro de uma agência pelo Presidente da República simplesmente pelo fato de que aquele não seria útil 'à implantação das diretrizes da nova administração?.

Os poderes regulatórios concedidos pelo Congresso às Agências são geralmente de três tipos ${ }^{8}$. O primeiro é o poder de licença (licensing power), ou seja, o controle sobre a entrada em funcionamento das empresas do ramo. $O$ segundo é o poder de fixação de tarifas (ratemaking power). Finalmente, têm as agências o gigantesco poder de controle das práticas negociais (power over busines practices), mediante o qual têm a autoridade de aprovar ou proibir determinadas práticas econômicas das empresas sob sua competência.

No campo das telecomunicações, a primeira tentativa de regulamentação foi feita pela Lei Mann-Elkins (Mann-Elkins Act, 1910), que atribuiu à própria ICC responsabilidade sobre os serviços interestaduais de telefone, telégrafo e serviços de utilização de cabos. Em 1927, a caótica indústria radiofônica foi posta sob o comando dè uma Federal Radio Commission (FRC), responsável pela concessão de licenças de funcionamento e determinação de faixas de frequiência ${ }^{9}$

A Lei Federal de Comunicações (Federal Communications Act, 1934) criou a Federal Communications Commission (FCC), atribuindo-lhe todas as funções da FRC (que foi extinta), as atribuições da ICC nas telecomunicações e dando-lhe a formidável atribuição de "estabelecer políticas de regulamentação das comunicações interestaduais e internacionais por televisão, rádio, fios, satélites e cabos", segundo a redação que lhe foi posteriormente dada pela Lei de Telecomunicações (Telecommunications Act, 1966).

B) FCC: escopo e atuação.

A Constituição americana de 1787 não possui, obviamente, dispositivos regulamentadores das telecomunicações. De fato, a Constituição preocupou-se com a comunicação interestadual ao atribuir ao Congresso o poder de "estabelecer agências e vias postais" (Art. $1^{\circ}$., seção 8,7 ). No entanto, o fulcro do poder regulatório da FCC, assim como o de quase todas as agências federais, encontra-se na chamada Commerce Clause, Cláusula do Comércio, pela qual o Congresso pode "regular o comércio com as nações estrangeiras, entre os vários Estados e com as tribos indígenas" (Art. $1^{\circ}$., seção 8, 3).

O engrandecimento da Commerce Clause pela interação da interpretação histórica da Suprema Corte com a vontade do Congresso forma um significativo capítulo da história constitucional americana, envolvendo complexas noções de soberania

Ibid., p. 29.

9 Pegrum, 1965, p. 649. 
dos Estados-membros e limitação dos poderes federais. Seria justamente durante a década de 1930 que, como efeito das políticas do New Deal, a Suprema Corte deferiria abertamente à intenção congressual de regulamentar aspectos intra-estaduais do comércio interestadual ${ }^{10}$.

A única diretriz fixada inicialmente pelo Congresso para a atuação da FCC foi o zelo pela "conveniência, interesse e necessidade públicas" "1 na regulamentação, missão efetivamente ampla e sinalizadora da hesitação do legislador em assinalar metas e objetivos públicos específicos em um campo eminentemente técnico e dinâmico ${ }^{12}$, garantindo simultaneamente a preeminência do interesse do consumidor nos processos decisórios da agência. Nesse contexto, ausentes determinações legislativas quanto ao tratamento de questões mais específicas, a atuação da FCC passou a ser pautada, conforme a tradição americana, pelo posterior controle judicial dos atos administrativos através do Judiciário Federal.

As posições mais significativas assumidas pela Suprema Corte em relação à FCC passaram a enfatizar a garantia de que o consumidor de serviços de telecomunicações fosse ouvido, especialmente nos casos de concessões ${ }^{13}$ de radiofrequiências e suas renovações. Conforme expôs a Corte em 1966, a função pública da agência e a presunção de que seus atos seriam norteados pelo interesse do consumidor devem ser relativizadas quando há expressiva prova da insatisfação do público com os serviços prestados pelos concessionários ${ }^{14}$.

\section{C) FCC e a Proteção da Concorrência.}

A função primordial da FCC é proteger os interesses do consumidor em todas as indústrias por ela reguladas, de modo a "assegurar menores preços e maior qualidade aos consumidores de telecomunicações" " . A atuação da FCC na defesa do consumidor pode ser direta, como na correção da tarifas abusivas, ou indireta, como quando da negativa de renovação de determinada concessão. Dentre as medidas indiretas tomadas pela FCC, são extremamente significativas aquelas destinadas à promoção da livre concorrência.

O maior propósito das mudanças trazidas pela Lei de Telecomunicações de 1996, a primeira peça legislativa a alterar a estrutura e metas da FCC desde sua criação, foi o de aumentar a competição econômica em todas as subdivisões do setor.

10 National Labor Relations Board V. Jones \& Laughlin Steel Corp., 301 U.S.I (1937). In: COX The Court and the Constitution. Boston, 1987, p. 156-173.

11 Federal Communications Act, ementa.

12 Rosembloom, 1989, p. 364.

13 Na realidade, licenças de funcionamento (licenses), não sendo o espectro de freqüiências de propriedade estatal.

14 Office of Communication v. FCC, $359^{\circ}$ F.2d994 (D.C. Circ. 1966). In: SCHWARTZ, 1988, p. 449.

15 Telecommunicattions Act, ementa. Esta mesma lei define telecomunicações, para o Direito americano, como "a transmissão, entre pontos especificados pelo usuário, de informação de sua escolha, sem qualquer alteração na forma ou conteúdo da informação em seu envio ou recepção". 
Como órgão de estímulo à concorrência, adstrita a seu poder de controle sobre as práticas negociais, a FCC atua em duas posições.

Primeiramente, a FCC deve agir preventivamente, evitando conceder licença de atividades similares às mesmas empresas em uma mesma região e impedindo a existência de qualquer tipo de exclusividade territorial ou, no caso das comunicações de massa, de programação. Deve ainda impedir e punir a prática de preços predatórios praticados por uma empresa com o intuito de inviabilizar economicamente suas concorrentes $^{16}$. Ademais, a FCC pode atuar posteriormente, proibindo, regulando e normatizando, ainda que em níveis muito específicos, a concentração econômica no setor.

\section{Agência Nacional de Telecomunicações (ANATEL): origem e funções} genéricas.

\section{A) Agências Reguladoras no Brasil: terminologia e histórico.}

O termo "agência", em seu significado jurídico-administrativo, foi introduzido no Brasil durante a década de 1990, advindo do direito americano. Ao criar esses novos entes administrativos, o legislador brasileiro visou estabelecer autarquias nos moldes das regulatory agencies, francamente ligadas à Administração Direta (semelhantemente aos entes autárquicos tradicionais), mas amplamente autônomas da hierarquia decisória do Executivo federal.

O principal meio pelo qual o legislador pretendeu dar autonomia decisória plena às agências, inspirado no conceito americano, foi através da organização de conselhos diretores compostos por membros com mandatos fixos. Embora haja doutrinadores que rejeitem a possibilidade de uma agência freqüentemente divorciada da direção do Presidente da República (nos termos do Art. 84, II, da Constituição Federal ${ }^{17}$, a interpretação do texto legal dependerá da definição dos tribunais, como ocorreu com a Suprema Corte dos Estados Unidos no caso Humphrey's Executor (supra, 1, A).

Foi a Lei 9.427/1996, disciplinadora do sistema de distribuição de energia elétrica, que introduziu no direito brasileiro tanto o novo termo quanto o próprio conceito de agência reguladora ao criar a Agência Nacional de Energia Elétrica (ANEEL).

Além da agência reguladora, o direito administrativo brasileiro contemporâneo alberga a "agência executiva". Esta, no entanto, se trata apenas de um ente administrativo anteriormente existente que, através de contrato de gestão com o poder público, ganha maior autonomia gerencial com a finalidade de aumentar sua eficiência (Art. 37, $\S 8^{\circ}$ da Constituição Federal, com redação determinada pela Emenda Constitucional $n^{\circ} 19 / 1998^{18}$ ).

16 Vide Telecommunications Act, seçōes 301 e 302

17 Pietro, 2000, p. 385.

18 Ibid., p. 388. 
Antes mesmo da criação da ANEEL, a Emenda Constitucional n. 8/1995, liberalizadora das telecomunicações, estabelecera a necessidade da criação de um "ógão regulador" para o setor. Foi no bojo da Lei Geral de Telecomunicações (LGT - Lei 9.472/1997), reorganizadora das comunicações, que foi criada a Agência Nacional das Telecomunicações, primeira agência reguladora advinda de expressa determinação constitucional.

À ANATEL foi dado o caráter de autarquia (Art. $8^{\circ}$ ), com a conceituação adicional de "autoridade administrativa independente" (Art. $9^{\circ}$ ), denominação de origem francesa ${ }^{19}$. Como as agencies americanas, a ANATEL apresenta como órgão diretivo máximo um Conselho Diretor, composto por cinco membros com mandatos fixos de sete anos (reduzidos para cinco anos pela Lei 9.986/2000), escolhidos pelo Presidente da República e por ele nomeados após aprovação do Senado Federal.

O Conselho Diretor tem várias atribuições legais (Art. 22), duas das quais afiguram-se muito significativas: a edição de normas sobre todas as matérias de competência da Agência (definidas pela LGT) e processar todas as outorgas para prestação de serviço público de telecomunicações, dos editais de licitação à extinção de concessão.

\section{C) Atribuições Legais da ANATEL.}

A LGT define o serviço de telecomunicações como um "conjunto de atividades que possibilita a oferta de telecomunicação" (Art. 60) ${ }^{20}$. Com a finalidade de regular as diferentes atitudes do Poder Público perante os prestadores do serviço, a LGT diferencia os serviços de telecomunicações entre aqueles "de interesse restrito" e os "de interesse coletivo". Estes podem ser, por sua vez, ser classificados em públicos e privados, segundo o regime jurídico correspondente.

Detentora do poder de licença (licensing power, supra, 1-A), a ANATEL tem o controle sobre o funcionamento regular das prestadoras de serviços de interesse coletivo. Os serviços em regime público, obrigados à universidade e à gratuidade, são o núcleo das ações da Agência, que lhes garante o funcionamento por contrato de concessão ou, excepcionalmente, por permissão. Paralelamente, os serviços em regime privado dependem de termo de autorização da Agência.

O artigo 19 da lei estabelece detalhadamente as atribuições da Agência reguladora, que deve ser norteada pelo interesse público, buscando o desenvolvimento das telecomunicações no Brasil, sempre sob as diretrizes constitucionais da Administração Pública. Dentre várias competências genéricas, destacam-se aquelas que têm maiores implicações para o usuário, a defesa de seus direitos e a repressão das

19 Cavalcanti, 2000, p. 262.

20 A LGT define telecomunicaçã̀o, para o Direito brasileiro, como "a transmissão, emissão ou recepção, por fio, radioeletricidade, meios ópticos ou qualquer outro processo eletromagnético, de símbolos, caracteres, sinais, escritos, imagens, sons ou informaçōes de qualquer natureza" (Art. 60. $s 1^{n}$.). 
infrações a estes e que fazem da ANATEL um membro inequívoco do Sistema Nacional de Defesa do Consumidor (Art. 105 da Lei 8.078/1990).

\section{ANATEL e Proteção do Consumidor.}

\section{A) Defesa do Consumidor e Direitos do Usuário de Serviços de Telecomunicações.}

Um dos princípios mais relevantes no disciplinamento das relações entre os sujeitos dos serviços de telecomunicações é o da defesa do consumidor, garantido pela Constituição Federal e explicitado pela Lei Geral de Telecomunicações. Ao usuário de tais serviços, o ordenamento jurídico garante direitos vários, expressos no artigo $3^{\circ}$. da LGT e assegurados por várias disposições específicas da própria lei e que devem guiar os atos normativos estabelecidos pela Agência Nacional de Telecomunicações. Esses direitos do usuário podem ser compreendidos, de acordo com suas similaridades, a partir do objeto jurídico protegido.

O usuário tem protegido, primeiramente, seu acesso aos serviços de telecomunicações, que deve ser de qualidade padronizada e regularidade adequada, em caráter nacional (LGT, Art. $3^{\circ}$, inc. I) livre na escolha do prestador (inc. II), não estando sujeito à discriminação de condiçōes e de fruição (inc. III). Ademais, o acesso não pode ser interrompido, a não ser por descumprimento de relações contratuais ou débitos vinculados diretamente ao serviço de regime público correspondente (inc. VII).

Ao consumidor deve ser igualmente garantida a informação sobre as condições e tarifas dos serviços prestados (inc. IV), incluído o prévio conhecimento das condições de suspensão (inc. VIII), além do direito de receber respostas às suas reclamações (inc. X).

Igual ênfase é dada pelo legislador à proteção da privacidade do usuário quanto à inviolabilidade de sua comunicação (inc. V), do seu código de acesso (inc. VI) e dos documentos de cobrança e dados pessoais (inc. IX) ${ }^{21}$.

O direito constitucional de petição ao Poder Público (especificamente à ANATEL e aos órgãos de proteção ao consumidor) para a defesa de direitos é enfatizado (inc. XI). A violação de qualquer de seus direitos, enumerados ou não, dá ao consumidor o direito de ser reparado (inc. XII).

\section{B) Poder Normativo da Agência Reguladora e Proteção do Consumidor.}

Uma das mais significativas competência da ANATEL, e aquela que lhe dá a feição característica de órgão regulador, é a elaboração de normas, dentro do poder geral das agências reguladoras de definição das práticas negociais (supra, 1-A). Tais

21 Tanto o código de acesso (e.g. número telefônico) quanto os dados pessoais serão mantidos em sigilo, havendo requisição do usuário para tanto. 
normas podem dispor tanto sobre a "outorga, prestação e fruição dos serviços de telecomunicações no regime público" (LGT, Art. 19, inc. IV) quanto sobre a prestação desses no regime privado (inc. $\mathrm{X}$ ) e até quanto aos equipamentos utilizáveis pelas prestadoras (inc. XII).

Formalmente, o poder normativo da Agência é exercida pela edição de resolução por seu Conselho Diretor (supra), no formato de regulamentos, planos e normas propriamente ditas ${ }^{22}$. Na defesa do consumidor, esse amplo poder normativo pode-se apresentar de duas maneiras.

Primeiramente, através da ação direta, com a criação de normas complementares às estabelecidas em lei, integradoras dos direitos criados por esta, ou formadora de direitos novos dos usuários. Desta maneira, tendo a lei fixado um determinado direito do usuário, à norma da Agência cabe definir tal direito, estabelecer as sanções ao seu descumprimento e esclarecer as circunstâncias que possam isentar a prestadora de serviços de culpa por aparente infração a direito ${ }^{23}$. A ANATEL pode mesmo fixar as cláusulas indispensáveis e as proibidas nos contratos firmados entre usuários e prestadoras de serviço ${ }^{24}$.

O poder normativo da Agência também se manifesta indiretamente, protegendo o consumidor como elemento da estrutura geral de telecomunicações. Ao estabelecer padrões técnicos determinados ou adotar modelos específicos de serviços, a ANATEL dá ao consumidor a faculdade de verificar a qualidade do serviço fornecido. Ademais, a uniformização de padrões técnicos facilita a universalização dos serviços de telecomunicações e reduz os custos para todos os integrantes do sistema consumidores, prestadores e o próprio órgão fiscalizador.

A Agência protege os interesses do usuário de forma indireta ao fixar normas que garantam a segurança do sistema e impeçam a concentração econômica no setor (infra). Ao editar normas que visam impedir a interferência mútua de sinais de telecomunicações, a Agência não visa exclusivamente compor os interesses das prestadoras (que é também função sua, segundo a LGT, Art. 19, inc. XVII), mas também propiciar ao usuário qualidade nos padrões de telecomunicações ofertados.

\section{C) Fixação de Tarifas e Defesa do Consumidor}

O terceiro grande poder das agencies americanas também é exercido pela ANATEL na fixação de tarifas (rate-making power, supra, 1-A), tarefa que lhe é

22 O Regulamento dos Serviços de Telecomunicações, anexo à Resolução n 73/1998, define os tipos de atos normativos expedidos pela Agência.

23 A LGT estabelece, por exemplo, o direito do usuário à continuidade do serviço (Art. $3^{\circ}$, VII), que é dever de todo prestador de regime público (Art. 63, parágrafo único). O Regulamento dos Serviços de Telecomunicações (anexo à Resolução n 73/1998 da ANATEL) define a obrigação da continuidade ("fruição de forma ininternupta, sem paralisações injustificadas", Art. $44, \S 2^{\circ}$.), esclarecendo todavia que a "interrupção circunstancial do serviço decorrente de situação de emergência (...) não será considerada violação da continuidade” (Art. 45).

24 Em modelo similar ao que ocorre com a fixação de cláusulas de contratos de seguros pelo governo federal, através da Superintendência de Seguros Privados (SUSEP), ente autárquico federal. 
firmemente assinada pelo legislador (LGT, Art. 19, inc. VII; Arts. 103-109). De todos os poderes da Agência, o de estabelecer as estruturas tarifárias para os serviços de regime público está entre os mais perceptíveis para os usuários.

O poder da ANATEL na determinação da estrutura tarifária é, em geral, limitado pelo que for acordado entre a Agência (concedente) e a prestadora de serviços (concessionária) no contrato de concessão. Naturalmente, como em todo contrato administrativo típico, a concessão do serviço de telecomunicações obedecerá à vontade contratual unitária da Administração Pública, conforme fixada anteriormente em edital ${ }^{25}$.

A LGT reserva à Agência a possibilidade de instituir regime de liberdade tarifária, quando houver competitividade efetiva em determinado ramo de serviço, e de suspendê-lo, em caso de aumentos abusivos (Art. 104). A fim de impedir o abuso do poder econômico, a própria LGT determina que as reduções e descontos promovidos pelas concessionárias sigam critérios objetivos e atinjam indistintamente os usuários (Arts. 106 e 107), tendo estes direito a descontos em caso de ganhos econômicos não advindos de aumento da eficiência e produtividade da empresa.

Assim como ocorre nos contratos celebrados com a Administração em geral ${ }^{26}$, a álea econômica, ou seja, as alterações de caráter econômico externas ao contrato e à vontade das partes, e a álea administrativa do fato do príncipe ${ }^{27}$, alterações administrativas externas ao contrato, implicam a revisão do contrato de concessão de serviço de telecomunicações (LGT, Art. $108, \S 4^{\circ}$ ). Esta revisão pode alterar consideravelmente a política tarifária da concessionária.

\section{A Agência e a defesa da concorrência.}

Uma das funções essenciais da ANATEL é a defesa da concorrência nos serviços de telecomunicações, através da "prevenção e repressão das infrações da ordem econômica" (LGT, Art. 19, XIX). Ressalvada a responsabilidade do Conselho Administrativo de Defesa Econômica (CADE) ${ }^{28}$, todos os atos abusivos à ordem econômica cometidos por prestadores de serviços de telecomunicações submetem-se ao controle sancionador da Agência, em obediência à determinação constitucional ${ }^{29}$.

A norma administrativa fundamental para a promoção e proteção da concorrência no setor de telecomunicações é a Norma ANATEL no $7 / 1999^{30}$, que fixa os procedimentos administrativos relativos ao controle preventivo, à apuração e à repressão de atos abusivos (infracionais) da ordem econômica.

Inicialmente, é da responsabilidade da ANATEL o controle antecipado dos "Atos de Concentração", assim estendidos aqueles que possam limitar ou prejudicar

26 Lei 8.666/1993, Art. 58.

27 DI PIETRO, 1989, p. 142-143.

28 Transformado em autarquia pela Lei 8.884/1994, a "Lei Antitruste" brasileira.

29 Constituição Federal, Art. 170 e Art. 173, § $4^{\circ}$.

30 Aprovada pela Resolução n¹95/1999 da ANATEL. 
a livre concorrência ou ainda resultar em dominação de mercado ${ }^{31}$. Em todos os ramos da indústria sob sua competência administrativa, a ANATEL desempenha a função antitruste que ordinariamente cabe conjuntamente à Secretaria de Acompanhamento Econômico (SEAE) e à Secretaria de Direito Econômico (SDE), nos termos do Artigo $7^{\circ}$. da LGT. A Agência deve encaminhar ao CADE, no prazo de sessenta dias, análise dos atos de concentração analisados, para julgamento pelo plenário deste órgão.

A Agência também deve atuar repressivamente, sempre que apurar indícios de infração à ordem econômica no setor de telecomunicações, em posição similar à da SDE. A Norma ANATEL n 7/1999 enumera os indícios que permitem a instauração de processo administrativo contra a prestadora de serviços investigada. A esta são garantidos todos os direitos constitucionais do procedimento administrativo, enquanto reserva a quaisquer interessados, inclusive consumidores afetados, a possibilidade de intervir no processo (Art. $4^{\circ}$.).

Finalmente, observe-se que a LGT determina que a cisão, a fusão, a transformação, a incorporação, a redução de capital e a transferência de controle societário de empresas concessionárias do setor de telecomunicações dependem de aprovação prévia pela ANATEL (Art. 97). Mesmo que aprovadas pela Agência, tais atos dependerão, em sua maioria, para sua efetivação, de submissão à aprovação pelo $\mathrm{CADE}^{32}$.

\section{Considerações Finais.}

$O$ curto tempo de sua existência justifica o pequeno interesse gerado pela Agência Nacional de Telecomunicações no direito brasileiro. Não se deve subestimar, no entanto, o caráter potencialmente transformador que a ANATEL, como as demais Agências, pode ter na Administração Pública brasileira, na profissionalização e dinamismo crescentes na burocracia federal e nas relações do poder estatal com a população usuária dos serviços públicos.

Para o consumidor, o Estado deixa de ser um provedor, com interesses contrapostos aos seus, passando a ser um aliado na fiscalização dos serviços públicos. Fortalece-se a posição da Administração, cujo objetivo maior em relação aos serviços públicos impróprios torna-se o controle de sua execução.

No entanto, para que as Agências reguladoras brasileiras, inclusive a ANATEL, possam usufruir da confiança da sociedade brasileira, é necessário assegurar sua autonomia decisória plena. Apenas quando livres da poderosa influência da indústria regulada e razoavelmente autônomas em relação à persistente intromissão do chefe do Poder Executivo é que as Agências poderão cumprir a relevante missão que lhes foi atribuída quando de sua transplantação teórica do direito americano das agêncies ao direito brasileiro.

31 Nos termos do Artigo 54 da Lei 8.884/1994.

32 Art. 54, caput, da Lei 8.884/1994. 
6. Referências Bibliográficas.

CAVALCANTI, Francisco de Queiroz Bezerra. A Independência da Função Reguladora e os Entes Reguladores Independentes. Revista de Direito Administrativo, v. 219, p. 253-270, jan./mar. 2000 .

COX, Archibald. The Court and the Constitution. Boston: Houghton Mifflin, 1987.

DI PIETRO, Maria Sylvia Zanella. Direito Administrativo. 12. ed. São Paulo: Atlas, 2000.

Do Direito Privado na Administração Pública. São Paulo: Atlas, 1989.

PEGRUM, Dudley F. Public Regulation of Business. Homewood, Illinois: Irwin, 1965.

ROSEMBLOOM, David H. Public Administration: Understanding Management, Politics, and Law in the Public Sector. 2. ed. New York: Random, House, 1989.

SCHWARTZ, Bernard. Administrative Law: A Casebook. 3. ed. Boston: Little, Brown and Company, 1988.

STILlMAN, Richard J. (Org.) Public Administration: Concepts and Cases. 5. ed. Boston: Houghton Mifflin, 1992. 


\section{Curso de Direito Romano}

José Carlos de Matos Peixoto

jose Carlos de Matos Peixoto

CURSO DE DIREITO ROMANO

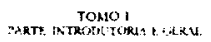

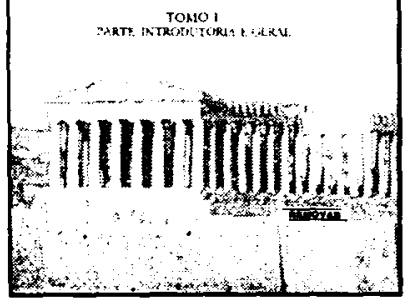

Trata-se de obra que se inclui entre as clássicas da nossa literatura jurídica, e que serviu de livro fundamental para a formação de inúmeras gerações de estudiosos do direito. Merece ser lida por todos aqueles que pretendem aprofundar seus conhecimentos juridicos, para o que são indispensáveis sólidas noçōes de história do direito, especialmente do direito romano.

Ref. 0137

Form. 16x23
Encadernado

1997
412 págs. $4^{\mathrm{a}}$ ed.

\section{Curso de Organização Judiciária \\ José de Souza Gama}

Esta obra é de grande utilidade para o estudioso do Direito, pois trata dos temas mais relevantes da disciplina. Para ser bem sucedido em sala de aula, concurso público e exame de ordem, será preciso dominar, conhecer profundamente, a estrutura do CODJERJ e do REGIMENTO INTERNO DO TJ, sabendo onde estão e o assunto tratado em cada livro, título, capítulo e seção.

Ref. 0174

Cartonado

Form. 16x23

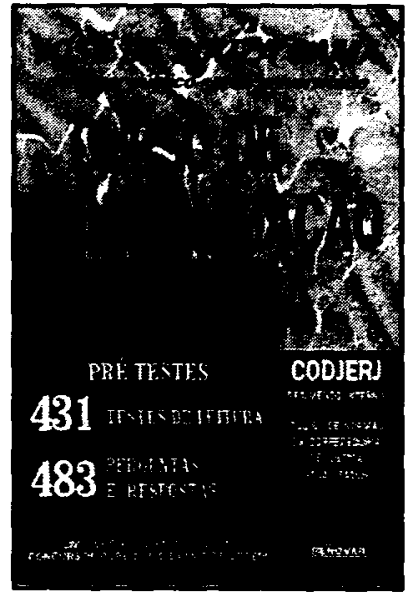

